\title{
Research Plans for a Mid-depth Cabled Seafloor Observatory in Western Canada
}

\author{
Verena Tunnicliffe, Richard Dewey and Deborah Smith \\ VENUS Project \\ University of Victoria $\cdot$ Victoria BC Canada
}

As the first cabled seafloor observatory that involves a geographically distributed network structure, the Victoria Experimental Network Under the Sea (VENUS) will oversee the deployment of three powered fiber-optic cable lines in British Columbia's (B.C.) southern waters. The funded infrastructure will offer two-way high-speed communication access and interaction in 24-hour real time from the ocean floor and water column to a land based location. With an expected life of at least 20 years, each cable line will have a unique set of instrument suite combinations that will reflect the environmental processes being studied by participating scientists and researchers. Internet access to data will be available for all: collaborators, scientists, students and the public. This new approach to sharing data will undoubtedly change the pace of understanding about the oceans for both the scientific community and the general public.

\section{The Vision for VENUS}

The concept for VENUS was derived from discussions of Canadian involvement with the NEPTUNE project. We link closely with NEPTUNE developments but VENUS has separate goals, clientele and funding. Our incentive is twofold: i) the need for better access to the dynamic ocean between Vancouver Island and the mainland and ii) the desire to entrain Canadian scientists into the cabled observatory concept. Impetus for a large regional cabled observatory off North America is growing but it will take time to develop new observational and data processing techniques. VENUS provides a learning base.

The Canadian Foundation for Innovation (CFI), provided initial funding to $40 \%$. This government corporation invests in Canadian research infrastructure. Funding decisions reflect capacity for innovation, training, and research collaborations. $40 \%$ of the project is funded from the British Columbia Knowledge Development Fund, which examines potential for economic enhancement from research infrastructure, and $20 \%$ came as in-kind contributions from industry and government partners. VENUS has a Can\$10.2 million budget over four years that is overseen by the University of Victoria.
Primary review, conducted by CFI, was based on the quality of science proposed and the ultimate researcher group. It is, however, only the infrastructure that is funded and an initial operating stage. A major challenge for VENUS is to find subsequent operational funds and to encourage the development of user groups. Thus, to write the proposal we involved the users. Over 30 scientists defined the mandate for VENUS and a subset crafted the proposal that requested funding for cable and seafloor node installations, shore stations and data management development plus some instruments to initiate research activity. The primary objective of VENUS is to support research into seafloor and water column processes at three locations. Data and user policies are in development but our expectation is: i) to provide a 24hour datastream to users; ii) to promote array access for additional instrumentation to funded researchers from any country; and iii) to allow web access to near realtime data from community instruments and as many investigator instruments as possible.

\section{Development of the Installation}

VENUS is a cabled ocean exploration project. VENUS cables will provide two-way full-time access and interaction to ocean and subsea environmental conditions for twenty years. Three separate cable lines will be laid in Saanich Inlet, Strait of Georgia, and Juan de Fuca Strait (Figure 1) with landfalls in British Columbia. With general sites selected by science groups to address issues of greatest interest; actual routing needs are under examination as science projects are reassessed and site surveys conducted. The first VENUS cable will be laid in Saanich Inlet in early 2004. Strait of Georgia and Juan de Fuca Strait cables will be laid with one cable ship deployment with nodes installed at depths of 300 and $170 \mathrm{~m}$ respectively. These second and third cables are planned for 2005. This aggressive schedule will see about $30 \mathrm{~km}$ cable laid across the Strait of Georgia from B.C.'s largest delta towards Vancouver Island. The funded Juan de Fuca Strait line will extend from Pedder Bay, B.C. southward to the border. Ongoing discussions with U.S. partners are assessing extension of the line to complete the crossing into Washington State-about another $10 \mathrm{~km}$. 

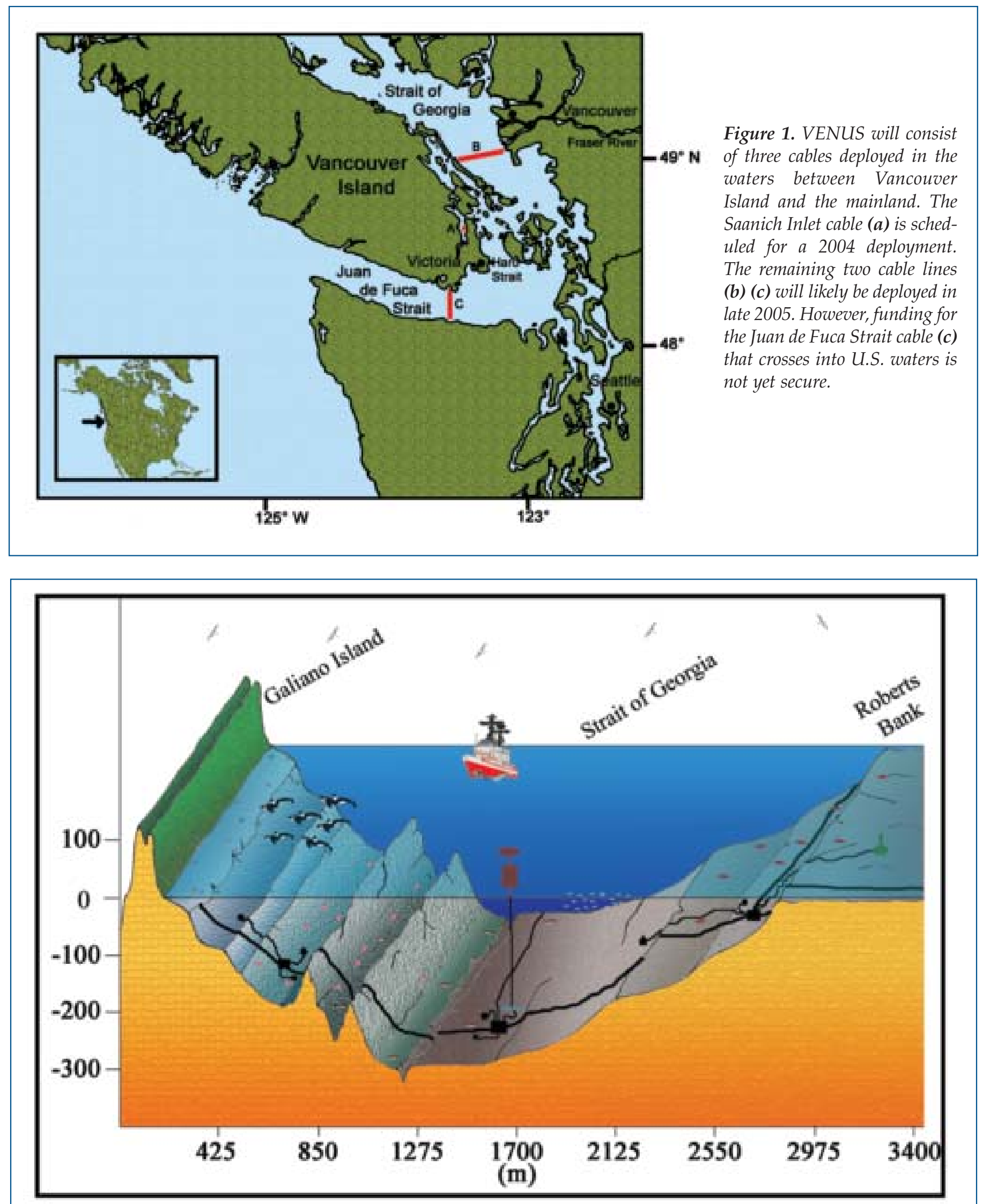

Figure 2. A cross-section of Strait of Georgia reveals the challenges in cable lay: first, through an active deltafront and secondly, over exposed bedrock ridges. The dynamic conditions that cause these features also attract researchers. A vertical profiler is planned for mid channel deployment as is an extension cable to a seismometer at an active fault $4 \mathrm{~km}$ to the north. 
A standard Alcatel telecommunications cable with eight optical fibers and a single power conductor has been purchased (Figure 2). Armoring varies dependent on bottom lay conditions. Up to ten kilowatts of shore power will be stepped down on the seafloor to deliver 48 volts DC to instruments (Howe et al., 2002). Multiple ports will be available for wet mateable connections to instruments that may extend several kilometers from the conversion node. Communication to seafloor instrumentation will be via stand Ethernet protocols with an IP address for each instrument using an optical transport layer. Saanich Inlet array will be the test bed for the telecommunications and power systems allowing for further development of the data management and control systems. Eventually, three shore stations will link with land lines (either directly or microwaved) to connect to the VENUS Data Management and Archive System. This developmental system will begin with standardized file transfer protocols but build to a formatting, display and interrogation design compatible with other ocean observing systems.

Each cable array will have a different combination of instrument packages reflecting the studies envisioned for that location: fish tag receiver, shoebox node, sediment dynamics package, major bottom package, vertical profiler and piezometer and/or seismometer. The Saanich Inlet cable will have one scientific node that will support multiple scientific packages; the Strait of Georgia and Juan de Fuca Strait will each have two nodes (or three if extended). While it will be possible to lift the node to the surface for repair, that operation will not be routine for connecting instruments. Either a submersible will plug a new instrument in on the seafloor, or a capped extension cord will be raised (by grappling or release) to the surface for ship-based deployment. VENUS installation and maintenance will rely heavily on ROV access to the array. One such vehicle is operated locally by the Canadian Scientific Submersible Facility: ROPOS is a $40 \mathrm{hp}$ ROV with two manipulators.

Major steps of the VENUS cable installation sequence include: define instrument locations in conjunction with the scientists most likely to conduct the research, define cable landing locations, select cable route, acquire government permits, perform cable route survey, finalize cable route and lay cable. The shore station and data management and archive system will be built in parallel. Workshops are convened to decide the locations at which the most investigations can be executed. Scientists explain their projects and location requirements to a group of fellow participants. These groups define the general locations but exact cable and node location is driven by the seafloor characteristics, permitting limitations and cable landing locations. The permitting process is a major rate-limiting step. Seafloor cables for scientific use have not been deployed in Canada thus existing regulations are not adequate. Informing the permitting agencies is a large component of staff time. We are in the process of networking with resource users such as trawlers to gain support for protection of the cables and instruments. Similarly, local public awareness and support of the cable locations/landings is considered important. In both cases, we argue that the long-term benefits of the results will benefit both the resource and society. We intend to promote support in the long term by seeking funding for public outreach programmes.

\section{Oceanographic Features of the Region}

A major factor in siting VENUS in Canada was the rich suite of ocean processes and ecosystems around Vancouver Island. Deglaciation created the numerous sounds and inlets along the British Columbia coast including the deep, broad channel of Juan de Fuca Strait that joins the inland basins of Puget Sound and Strait of Georgia with the Pacific Ocean. A marine temperate climate provides ample rain and snowmelt to coastal mountain rivers that drain into these basins with seasonal variability. Driven by this buoyant discharge, a large estuarine circulation is established through the Gulf and San Juan Islands before emptying through Juan de Fuca Strait onto the continental shelf west of Vancouver Island. This exchange is moderated by vigorous tidal currents and mixing, as the Strait of Georgia and Puget Sound respond to the mainly semidiurnal tidal forcing at the western entrance to Juan de Fuca Strait (Thomson, 1981).

Wind and tidal mixing enhances the estuarine exchange, which grows from $10^{5} \mathrm{~m}^{3} \mathrm{~s}^{-1}$ at the river mouths, to nearly $10^{6} \mathrm{~m}^{3} \mathrm{~s}^{-1}$ in Juan de Fuca Strait. A deep, saline inflow balances this flux and carries abundant nutrients, enhanced during the summer months by large-scale coastal upwelling over the continental shelf. High productivity throughout the region supports salmon and herring fisheries, as well as ecotourists who seek the resident marine mammals.

Circulation on the broad continental shelf west of Vancouver Island varies seasonally, with northward, downwelling conditions during the winter, and southward, upwelling conditions during the summer. As northern winds prevail from May through September, cold $\left(6^{\circ} \mathrm{C}\right)$, saline $(34 \%)$ up-welled waters move coastward. In the wide Juan de Fuca Strait, Coriolis effect pushes the deep eastward inflow along the southern side. The exiting, fresher surface flow, confined to the northern side of the Strait balances the salt transport, and establishes a broad sheared exchange flow, with isopleths sloping upwards to the south. Mixed semidiurnal tides are modified entering the Juan de Fuca Strait, as the shelf Kelvin wave propagates inland, where it drives strong tidal currents throughout the Strait. Eastward, the Strait shallows to $100 \mathrm{~m}$ and broadens. To the south are the narrow entrances to Puget Sound, through which strong tidal currents flow. To the northwest are headlands bending currents that can exceed $3 \mathrm{~m} \mathrm{~s}^{-1}$ at Race Rocks and Race Passage (Figure 3). Currents mix through a small group of rocks 


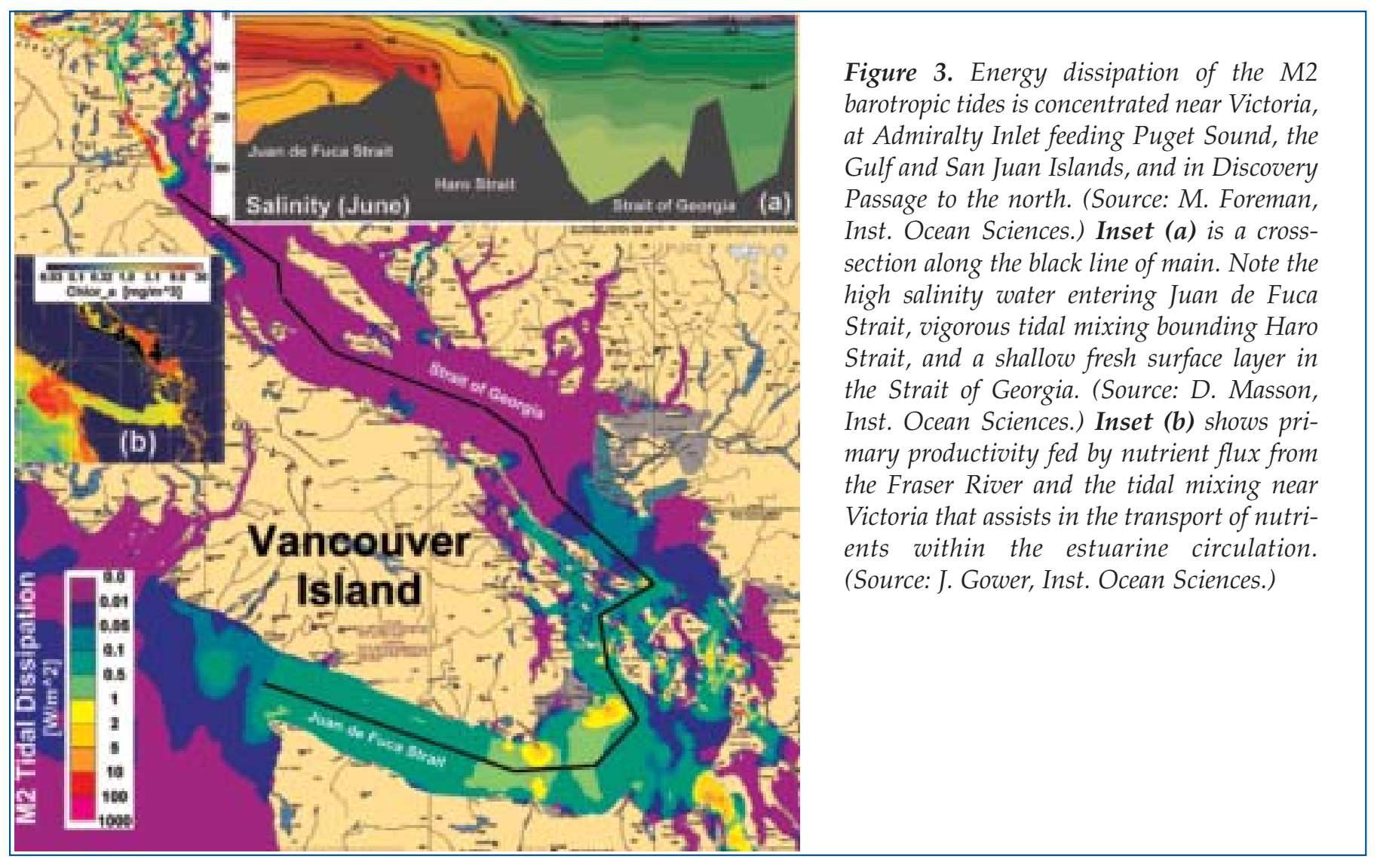

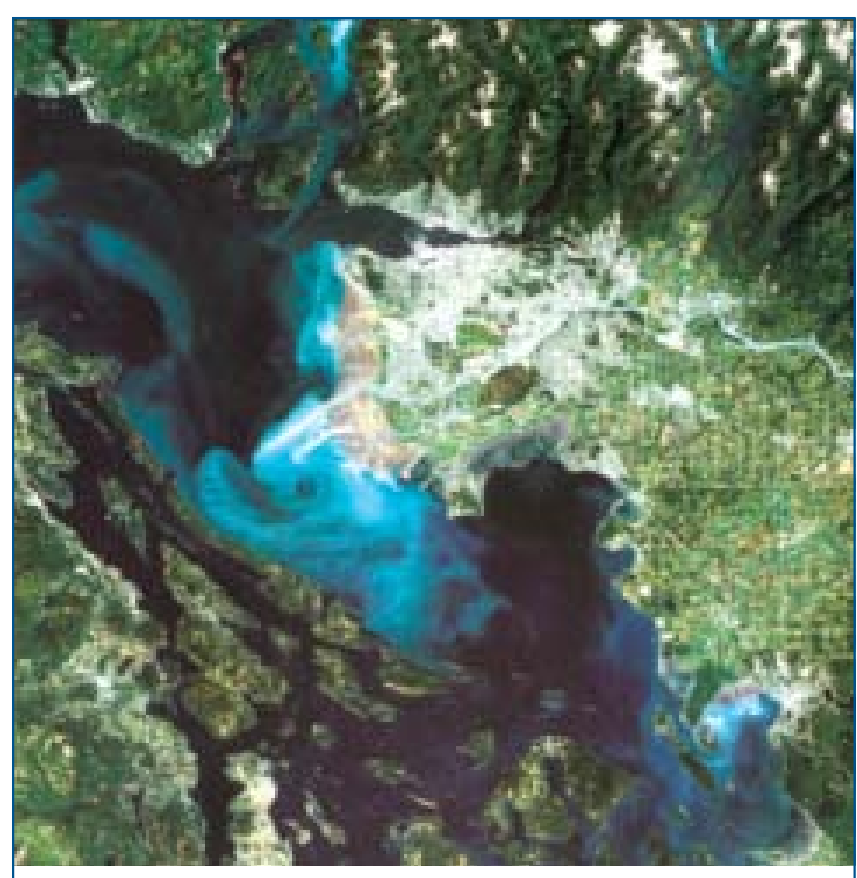

Figure 4. Landsat image of the sediment laden Fraser River plume, extending throughout the southern reaches of the Strait of Georgia. A large expanse of mudflat is evident at low tide. A ferry terminal, a deepsea vessel facility and a major breakwater are evident here. Sediment delivery is at a peak in late spring and early summer. (Source: National Research Council of Canada: http://geogratis.cgdi.gc.ca/clf/en.) and islands, east of Victoria before entering the deep (300 m) Haro Strait. The Gulf and San Juan Islands break the exchange flows into numerous narrow and winding channels.

Northward lies the Strait of Georgia (Figure 1) with the City of Vancouver and the Fraser River Delta on the eastern shore and Vancouver Island on the west. Most exchange with the Strait of Georgia occurs via the southern passages although substantial flows occur through Seymour Narrows in Discovery Passage, where tidal currents can reach $6 \mathrm{~m} \mathrm{~s}^{-1}$. Water characteristics are dominated by the seasonal freshet entering the Strait, most significant of which is the silty discharge of the Fraser River (Figures 3a and 4). Sediment loading along the delta is significant, and the southern Strait of Georgia seafloor is sculpted by episodic slope failures and dune migration. Depths exceed $400 \mathrm{~m}$. Nutrients from the Fraser River support a seasonal summer bloom that feeds higher trophic levels (Figure 3). Nutrients brought into Juan de Fuca Strait via coastal upwelling and the deep estuarine circulation, are mixed vertically into the surface waters by the vigorous tidal currents around Victoria and within the Gulf and San Juan Islands. This nutrient supply is important but the estuarine exchange transports much of the upwelled nutrients back out through Juan de Fuca Strait to the continental shelf (Figure 3b).

On to this oceanographic canvas is overlaid the pressures of over 5 million people living along the 


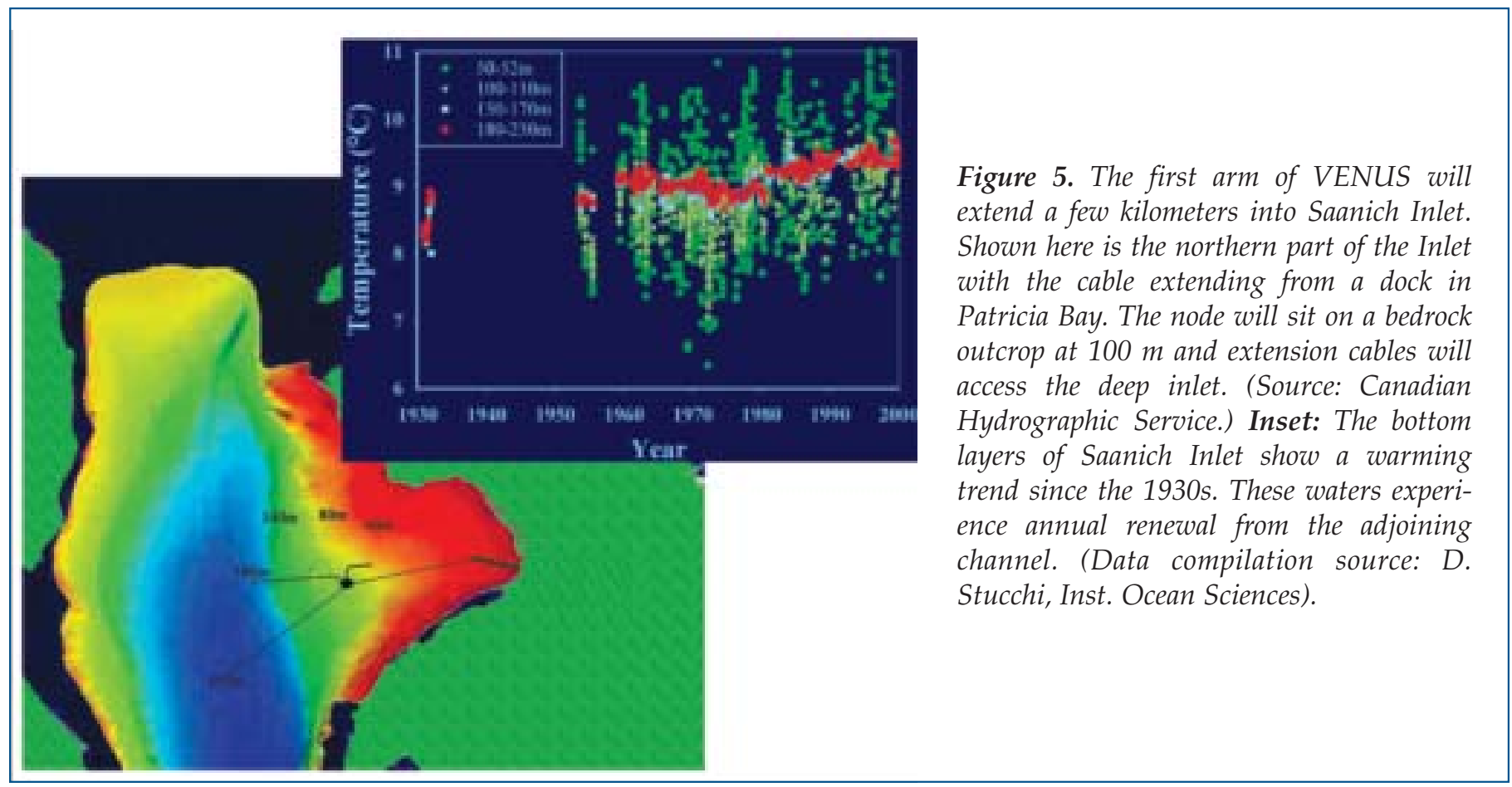

coastal regions of Vancouver Island, Puget Sound, and the Strait of Georgia. Recreational activities (sailing, boating, and fishing) are popular, as are commercial enterprises including forestry, fisheries, and commercial shipping. The vessels entering Juan de Fuca Strait to service the ports of Tacoma, Seattle, and Vancouver use the busiest shipping channel in North America. Navy bases in Victoria and Puget Sound contribute to the vessel variety seen in the Straits. In light of these regional activities and the complex oceanographic environments, VENUS is a timely endeavour.

\section{Research Opportunities in Saanich Inlet}

Saanich Inlet is one of the best-studied marine basins in the world because of its easy access and unusual properties. Flow into the deep inlet from tidally well-mixed waters in the Strait of Georgia is restricted by a shallow sill. High primary production from phytoplankton contributes organic matter to the deep water where degradation quickly depletes dissolved oxygen (Timothy and Soon, 2002). The result is hydrogen sulfide buildup in waters and sediments, a depleted infauna and annually varved sediments. Annual renewal of the deep waters occurs each autumn as dense, oxygenated waters move up the adjoining Straits. Saanich was the site of an Ocean Drilling Program to recover a fine-scale sediment record back to the Holocene (Bornhold and Kemp, 2001).

The first VENUS node will sit on a bedrock outcrop at $100 \mathrm{~m}$ depth (Figure 5). The site complements a surface buoy that is collecting irradiance, chlorophyll, wind and temperature information. A bottom ConductivityTemperature-Depth sensor (CTD) will allow interpretation of water mass changes during renewal. From the node, long extension cables will access deeper water and enable instrument recovery/servicing from the surface. Long-term deepwater records will provide better resolution of the apparent warming trend that is occurring in the deep Inlet (Figure 5 inset); another research objective is to examine changes in renewal dynamics and the links to water mass behaviour in the Straits of Georgia and Juan de Fuca.

Although VENUS is an installation, not a research program, we expect the attached instruments will both complement independent investigations and form the focus for an integrated study. The fluctuating chemical conditions in the Inlet attract many workers. Deployable chemical sensors are still in trial; we expect to see optrodes to track oxygen and sulfide levels within a few years. The site will be a test facility for methane sensor development. An acoustic profiler will be used to interpret zooplankton behavior as spring production and chemical conditions shift. Saanich is experiencing a return of depleted stocks of salmon, herring and hake; one study will examine fish behaviour from the "Zooplankton Acoustic Profiler" with respect to production, renewal and zooplankton abundance.

\section{Physical Oceanographic Studies}

Physical oceanography studies associated with VENUS fall into four broad themes: boundary interactions (e.g. waves and mixing), exchange flows (e.g. estuarine circulation), interdisciplinary studies (e.g. nutrient flux), and long term variations (e.g. El Niño and climate change). Bridging these approaches will be modeling efforts including tidal models, transport and chemical models, and biological ecosystem modeling. While VENUS will provide long-term fixed site observations, 
it is anticipated that ship-based programs will support short duration process studies to complement the findings and knowledge gained by VENUS instruments.

VENUS will initially include three instrument suites in direct support of physical oceanography: a limited number of major bottom packages (MBP), more numerous "shoe-box" packages (SBP), and two vertical profiler systems (VPS). The MBP will include CTD, oxygen sensor, upward looking ADCP, zooplankton acoustic profiler, optical backscatter, and a broadband hydrophone. The SBP will have only a CTD and hydrophone, and the VPS will include a CTD, fluorometer, radiation sensor, acoustic Doppler velocimeter for microscale velocity measurements, transmissometer, a video plankton recorder, optical plankton counter, and a digital camera. It is anticipated that up to two MBP each will be deployed on the Strait of Georgia and Juan de Fuca Strait sections. Similarly, each will have a VPS deployed near the deepest location $(300 \mathrm{~m}$ in the Strait of Georgia and $170 \mathrm{~m}$ in Juan de Fuca Strait). Six to eight SBPs will be distributed along the bottom in each Strait to map the near bottom temperature and salinity variations.

\section{Sedimentology Studies}

The Fraser River delivers large volumes of sediment to the Strait of Georgia mostly during the late spring runoff period. Suspended mud is carried into the Strait and dispersed by tidal currents (Figure 4). The City of Vancouver and adjacent municipalities reside on the Fraser Delta modifying shoreline and channels to provide farming, port, residential and industrial facilities. Offshore, extensive tidal flats trap sediments; a marked slope break occurs at about $10 \mathrm{~m}$ and the delta front extends to $300 \mathrm{~m}$ into the Strait of Georgia (Figure 2). Seafloor sediment accumulations are redistributed by suspended and bedload transport. Sidescan imagery reveals large bedforms to multimeter amplitudes; many are migratory.

Siting of the Strait of Georgia cable crossing is driven partly by the desire to instrument the Fraser Delta for two studies: sedimentary dynamics and slope stability. A movable laboratory will monitor all factors that influence sediment movement (currents, waves, tides, storms) including benthic boundary layer behaviour. Instrumentation will be complemented by ROV site surveys and ship-based sampling. Sediment transport will be evaluated in all its forms through a defined area via acoustic and optical instruments. The objective is to provide better parameterization for transport models and to examine the role of storms. The VENUS deployment will allow multiple observations over long periods thus overcoming limitations of bandwidth and duration experienced in prior studies.
Delta slope failure is a marine hazard with many ramifications (Clague et al., 1998). The lower British Columbia/Washington region lies in a seismically active zone at high risk for large earthquakes. Submarine slides on the Fraser Delta are an anticipated consequence. The main power and telecommunication lines to Vancouver Island may be ruptured, ferry and port terminals destabilized and low lying areas swept by ensuing tsunamis. The Geological Survey of Canada is a partner in the VENUS project to instrument the deltafront and examine loading behavior in sediments. Successive bathymetric surveys reveal that extensive mass wasting has occurred several times off the south arm of the Fraser River (McKenna et al., 1992). Sidescan imagery also reveals structures that may form from active downslope sediment movement.

Proposed instrumentation will examine the role of several factors in slope failure: earthquakes, storms and variable pore pressures generated from tidal pressure and fresh water seepage. Pockmarks indicate presence of methane gas that may be another destabilizing factor. The major instrument suite will be a network of piezometers to monitor pore pressure changes under variable loads. The proponents propose several boreholes (not cabled) with pressure sensors to penetrate lower sediment layers. Two landward sites on the delta are also drilled and instrumented. Real-time data acquisition through the VENUS infrastructure gives these methods of pore fluid monitoring great potential as an early-warning system of liquefaction events.

\section{Biological Studies}

Both the setting and the research proposed by other disciplines attracted many biologists to VENUS workshops. The researcher push is for instrument deployments that will sponsor integrated studies. Proposed biological research capitalizes on work to characterize water and flow characteristics, variability and sediment behaviour. VENUS provides the opportunity to examine biotic responses to physical parameters through long-term coordinated datasets. The major advantage of hardwired instruments is notification of unusual events that allow changes in sampling frequency or type, or even trigger a supplementary site visit. The vertical profiler will provide access upper water layers for plankton studies of patterns in primary production and zooplankton responses. One product will be groundtruth data for airborne examination of ocean colour characteristics-otherwise difficult to interpret in coastal settings. The optical plankton counter will follow a distinctive copepod species that overwinters at depth in Strait of Georgia-its surface emergence is important as food for juvenile 
salmon emerging from rivers (Mackas and Louttit, 1988). VENUS will join with another study to track dispersion patterns of these juveniles with implanted acoustic tags; we will know when (and which) individuals cross a picket fence of transceivers.

A cabled observatory is limited by instrumentation mostly confined to the bottom. But acoustic instruments are versatile tools for biological studies. We will use profilers of several frequencies to examine the movement patterns in zooplankton and nekton. New approaches to analysis enrich interpretation (Thomson and Allen, 2000). Bottom mounted hydrophones will support cetacean studies. The endangered killer whale pods are the major focus of study: vocalizations will be monitored in real time by an acoustic recognition system in development to provide information on pod identity, movement and communication behaviour. Audio feeds from the seafloor will be used for public outreach and education purposes.

The rich benthic environment opens many possibilities for studies through VENUS. Conservation concerns have targeted sponge reefs and coral beds for long-term monitoring via acoustic and visual means. All seafloor sites will be serviced by remotely operated vehicle thus providing the opportunity for sample returns. Another integrated study will examine the role of infrequent events in structuring benthic communities. Plankton blooms, storms and carcass falls will be the major triggers. Carcasses will be placed for a triple purpose: response of the benthic community, colonization of carcasses and public outreach. Instrumentation includes a remote benthic respirometer, cameras, shape-resolving sonar and mini-ROVs connected to the network. VENUS expects to sponsor a study that will support forensic studies.

\section{The Future}

While we overcome our installation hurdles (power, communication and physical designs; site access and permitting; natural challenges such as a dynamic seabed; budget management and a challenging timetable; security negotiations), we seek to build the clientele for VENUS. The advantage of a cabled observatory is real-time data; thus we endeavor to retain as open a data policy as possible. One study becomes greatly enriched by simultaneous data from another. Issues of data archiving and quality assurance remain challenges to be resolved. In the long term, interoperability with other observatories is also key for researchers wanting to integrate over large scales or to test developing models. Most tools we are now deploying are well known; an important measure of success will be the degree to which this observatory provides the impetus to develop new tools (e.g. chemical and molecular) for a new approach to oceanography. For further information, visit our website at www.venus.uvic.ca. ed

\section{Acknowledgements}

Our thanks to S. Caspersen and J. Rose for graphics help and to A. Round for information.

\section{References}

Bornhold, B. and A. Kemp, eds, 2001: Late Quaernary sedimentation in Saanich Inlet, British Columbia, Canada-Ocean Drilling Program Leg 169S. Mar. Geol. Special Issue, 174, 390 pp.

Clague, J.J., J.L. Luternauer, and D.C. Mosher, eds, 1998: Geology and Natural Hazards of the Fraser River Delta, British Columbia. Geol. Survey Canada Bull., 525, 270 pp.

Howe, B.M., H. Kirkham and V. Vorperian, 2002: Power system considerations for undersea observatories, IEEE Jour. Ocean Eng., 27(2), 267-274.

Mackas, D.L. and G.C. Louttit, 1988: Aggregation of the copepod Neocalanus plumchrus at the margin of the Fraser River plume in the Strait of Georgia. Bull. Mar. Sci., 43, 810-824,

McKenna, G.T., J.L. Luternauer, and R.A. Kostaschuk, 1992: Large-scale mass-wasting events on the Fraser River delta front near Sand Heads, British Columbia. Can. Geotech. Jour., 29, 151-156.

Thomson, R.E. 1981. Oceanography of the British Columbia Coast. Can. Fish. Aquat. Sci., Spec. Publ., 56, 291 pp.

Thomson R.E. and S.E. Allen, 2000: Time series acoustic observations of macrozooplankton diel migration and associated pelagic fish abundance Can. J. Fish. Aquat. Sci., 57, 1919-1931.

Timothy, D.A. and M.Y. Soon, 2002: Primary production and deep-water oxygen content of two British Columbian fjords. Mar. Chem, 73, 37-51.

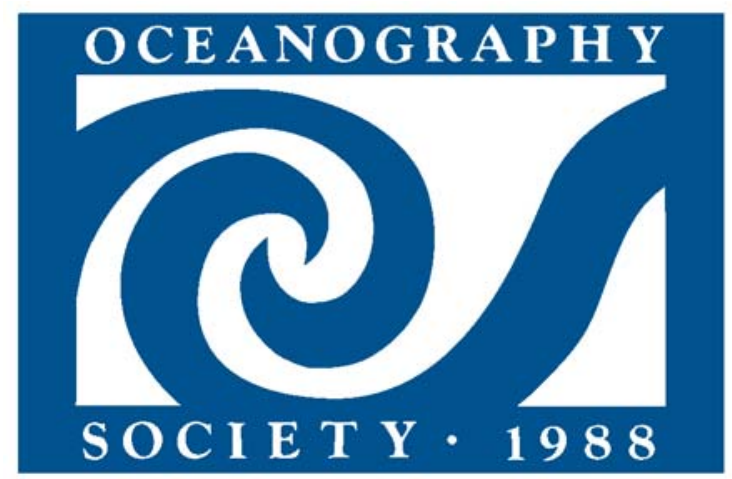

